\title{
The Taxonomy of the Functional and Structural Uses of Adverbs in Business Letter Writing in English
}

\author{
Jeyaseelan Gnanaseelan \\ English Language Teaching Unit, Vavuniya Campus of the University of Jaffna, Park Road, Vavuniya, Sri Lanka \\ E-mail: jeya86@hotmail.com
}

Received: 25-03-2016

Published: 01-09-2016
Accepted: 03-06-2016

doi:10.7575/aiac.ijalel.v.5n.5p.39
Advance Access Published: July 2016

URL: http://dx.doi.org/10.7575/aiac.ijalel.v.5n.5p.39

\begin{abstract}
This research analyses the types of the functional and structural uses of adverbs in letter writing in English revealing the linguistic and non-linguistic implications in both teaching and learning in the South Asian countries like Sri Lanka. It synthesizes, classifies and describes the types, functions, positions, quantity and quality and deviations. This is a case study of the texts produced by the students from Tamil and Sinhala language communities of Vavuniya Campus of the University of Jaffna in Sri Lanka. The analysis is both quantitative and qualitative. The findings distinguish the patterns and pragmatic uses typical of a non-native ESL learning context. It finds out that structurally prepositional phrase and single-word and functionally, time, place and manner dominate as adverbs in the use. The inefficient and ineffective use of noun phrase, adverb particle, adverbial clause, and sentence adverb, the learner incompetence of the distinction between adverb and the rest of the linguistic units, within their types and within their functions were identified and suggests a curriculum design or teaching methodology to incorporate this distinction.
\end{abstract}

Keywords: adverb, adverbial phrase, structure, function, position

\section{Introduction}

English language users or learners use the adverbs in English in considerable numbers and functions without understanding the deeper level implications and nuances. The use of adverbs shows the qualified or quantified relationship with an action denoted by a verb or its equivalent. An adverb qualifies or quantifies an action in real life situation or a use in terms of functions such as time, place and manner or process or a type. It increases or decreases the effect and efficiency of the action referred in the verb of the sentence. Nouns, noun phrases, adverb particle, prepositional phrases, adverb proper can form an adverb or adverbial phrase or adverbial function. They convey syntactic, semantic and pragmatic or discourse or ideological functions. Without realizing the inherent distinctions or taxonomic diversification, the learners and users handle adverbs which affects the teaching and learning of subjects taught in English medium. If the types and functions are not contrastively understood and applied, they impede competence and performance of the quantitative or qualitative modification, attribution of degree, number, and intensity of an action in the form of a verb in produced written texts. Ironically, the use of adverbs or teaching and learning them has been felt as a serious challenge to many teachers and learners and does not seem to pose many difficulties. Adverbs are significant structural and functional elements in form and meaning and they are essential discourse devices so complex and diverse in producing written texts. The roles of learning, teaching and using adverbs pose serious challenges for the persons assuming these three roles separately or collectively in a triangular role relationship.

\section{Need of the Study}

The teachers, learners and users of English as a second language in Sri Lanka, like others in the non-native English speaking countries use the adverbs in English writing without distinguishing different form and functional implications. Sri Lankans realize the need for being proficient in their use in their intra-sentential and inter-sentential functions and relations and denotations and connotations. Business letter writing is one of the key genres in training the business English writing skills of the university students at the undergraduate level or Bachelor's level (Gnanaseelan 2014). Though the use of adverbs in English does not cause serious inhibitions in 'fluent communication' in English by the natives of Sri Lanka, the Sinhalese and Tamil, taking this feature as granted and do have this system in similar forms, they continue to commit deviation structurally and functionally in their English discourse at the higher or complex level of communication in real life. They fail to show the form and functional distinctions in English.

\section{Theoretical Background}

Syntactically the adverbs are positioned in front of, in the middle and at the end of a sentence. The front position is adverbial fronting (Hewings, 2005). It can function as sentence adverb. It shows relation to a previous sentence or an emphasis. They are the most flexible units in the English language to be used anywhere- rule bound or rule free. Adverbs can shift position, but which often causes problems for ESL students (Hernández, 2006). However, the position after the main verb is generally considered as its usual position (Koffi, 2010). Literature texts, poetic or prosaic, maximum make use of this freedom and flexibility to communicate ideas and feelings so powerfully, efficiently 
and effectively. However, at the beginners' level, students can learn 'traditional default positions for adverbs' at the same time, learning 'the rhetorical emphasis of adverb repositioning' gradually (Dissosway \& Hartford, 1984). Zi-hong (2010) reminds the difficulty of capturing the rhetorical repositioning while learning or acquiring the syntactic positions of adverbs in English. There was a study which found out that good educational background and social class (middle) determine efficient use of adverb movement strategies more effectively compared to poor educational background and lower class (Macaulay, 2002).

Adverbs are words always joining with verbs in order to modify them. They try to define the action in some way. In addition their role is extended to 'express degree and limit adjectives or other adverbs (Baskervill and Sewell, 1896:18 as cited in Nuhiu, 2014). Adverbs are verb roots or adjectives which are formed with an -ly suffix depending on the situation (Eastwood, 1999:24 as cited in Nuhiu, 2014; Eckersley and Eckersley, 1960: 255 as cited in Al-Baghdadi 2003). They are parts of speech (Kabashi, 2000:20 as cited in Nuhiu, 2014). Adverbs are always connected with or contrasted with, related to, and compared to adjectives. In addition, adverbs are looked at another way but this is not possible with adjectives ending in (-ly). Alternative forms like "similar adverbs or adverb phrases" (Thomson and Martinet, 1980: 55 as cited in Al-Baghdadi 2003) are used.

The role of the prefixes in the formulation of derived adverbs: $a$ - as- and in- added to adjectives. The most common adverb suffix added to adjectives is -ly. Adverbs are "a heterogenous group of items" specifying "the mode of action of the verb." (Crystal, 1980:16 as cited in Al-Baghdadi 2003) "by giving circumstantial information in which an action, process takes place". (Finch, 2000:84 as cited in Al-Baghdadi 2003). Baskervill and Sewell (1896:282-87 as cited in Nuhiu, 2014) divide them in two ways: the meaning of the words and their use in the sentence. Time, place, manner, degree, number, assertion 'process' 'direction', 'movement', 'attachment or detachment', 'possession or dispossession' and 'context' (Eastwood, 1999:270-71 as cited in Nuhiu, 2014) belong to the former and simple and conjunctive adverbs belong to the latter. Quirk and Greenbawm, (1990:312-13 as cited in Nuhiu, 2014) propose two types: morphological and syntactical, closed class: simple and compound and opened class derivational adverbs. In different contexts, different adverbs may create different meanings causing meaning confusion. There is another type of adverb: adverbial emphasis as a receptive intensification. (Pérez-Paredes and Díez-Bedmar, 2012). They say it is a kind of linguistic grading that intensifies the quality to one's message; it is 'a vehicle for impressing, praising, persuading, insulting, and generally influencing the listener's reception of the message"” (p. 105).

In investigating the sequence of positioning adverbs, Hewings (2005) says when one adverbial is significantly longer, the shorter one should come first, regardless of the type. Rutledge and Fitton (2015) relate adverb positioning to the creation of sentence variety. The use of certain adverbs in certain positions repeatedly will result in redundancy in sentence style. It will "create stagnant sentence structure and relatively boring writing". So they suggest different positions. For example, the adverbs of frequency always, and never (Hewings, 2005) "take a fixed place in the mid position. They need to be placed after the subject and before the verb but the adverb of frequency, sometimes, can occur in all three positions". Adverb placement does not always rely on a semantic or syntactic relationship; rather adverb placement functions as a modifier but also as a distinctive variation for prominence (Jacobson, 1964). The stressed differences and the weight of adverb placement are a way to change pitch, stress, or junctural connectors in the sentence.

Delfitto (2006) is amused by "adverbial syntax leading to quite puzzling questions concerning the interplay between issues of placement and issues of movement" (p. 103). Rutledge and Fitton (2015) conclude that adverbial placement calls for particular cases of accuracy for clarity to eliminate ill-formed sentences and to develop rhetorical awareness and rhetorical emphasis in composition.

\section{Methodology}

It analyzes a business letter writing exercise in English performed by the second year students of the Bachelor of Business Management program of the Faculty of Business Studies of Vavuniya Campus of the University of Jaffna, Sri Lanka.

The methodology is qualitative and quantitative. It is a textual analytical approach under applied linguistics. During a Business English examination, as a part of the test, the students were asked to write "a letter of complaint to the Branch Manager of the Ceylon Electricity Board of their district regarding power cuts. As a customer and consumer of electricity power supply in their respective area, over the last three months, they have experienced severe, unscheduled, sudden and prolonged power cuts which have caused immense difficulties in managing day to day life in the area".

The texts from 84 students were collected. They were analyzed for authentic functional, structural, textual and linguistic relations and errors on the specified issues in the use of adverbs in the discourse of business letters. The primary data consist of both the quantitative and the qualitative. The quantitative data investigates the performance of all the respondents statistically for the estimation of the significance of the issue under study and the qualitative data analyzes the individual as well as collective performance using descriptive approach for generalization. The types of adverb errors or deviations have been coded in the table so that the codes substituting the names of the types of errors can be used in the analysis. 


\section{Analysis and Findings}

\subsection{Adverb Use and Types in the Discourse of a Letter of Complaint}

Figure 1 illustrates the quantity of the types of adverbs (178) used by the percentage of the respondents (84). Surprisingly $61 \%$ of the respondents used the prepositional phrase in adverbial function generously in their letter of complaint on power cut, that is, 39\% of the total adverbs used. The second and third come single word adverb (19\%) and single word adverb with $-1 \mathrm{y}(16 \%)$ suffix respectively. The former was used by $54 \%$ of the respondents and the latter by $64 \%$. Thereafter, noun phrase is used as adverb (11\%) used by $25 \%$ of the respondents. Another point noted was that in using prepositional phrases and noun phrases in sentences, the respondents showed lack of knowledge in distinguishing the function of adverb from that of subject or object complements.

However, the respondents did not show their proficiency in using any other phrases as adverb phrases, for example, 'very quickly' 'quickly enough' 'really well' 'quite separately' 'very carefully', 'right there', 'more than enough' and 'almost never'. Only $4.5 \%$ are the other adverb phrases used by $18 \%$. Adverb phrases are another area of difficulty for most of the respondents.

It is not surprising to note that only $2 \%$ are the adverb particles used as adverbs by merely $4 \%$.

Generally adverb particles follow the main verbs, for example, go off etc.

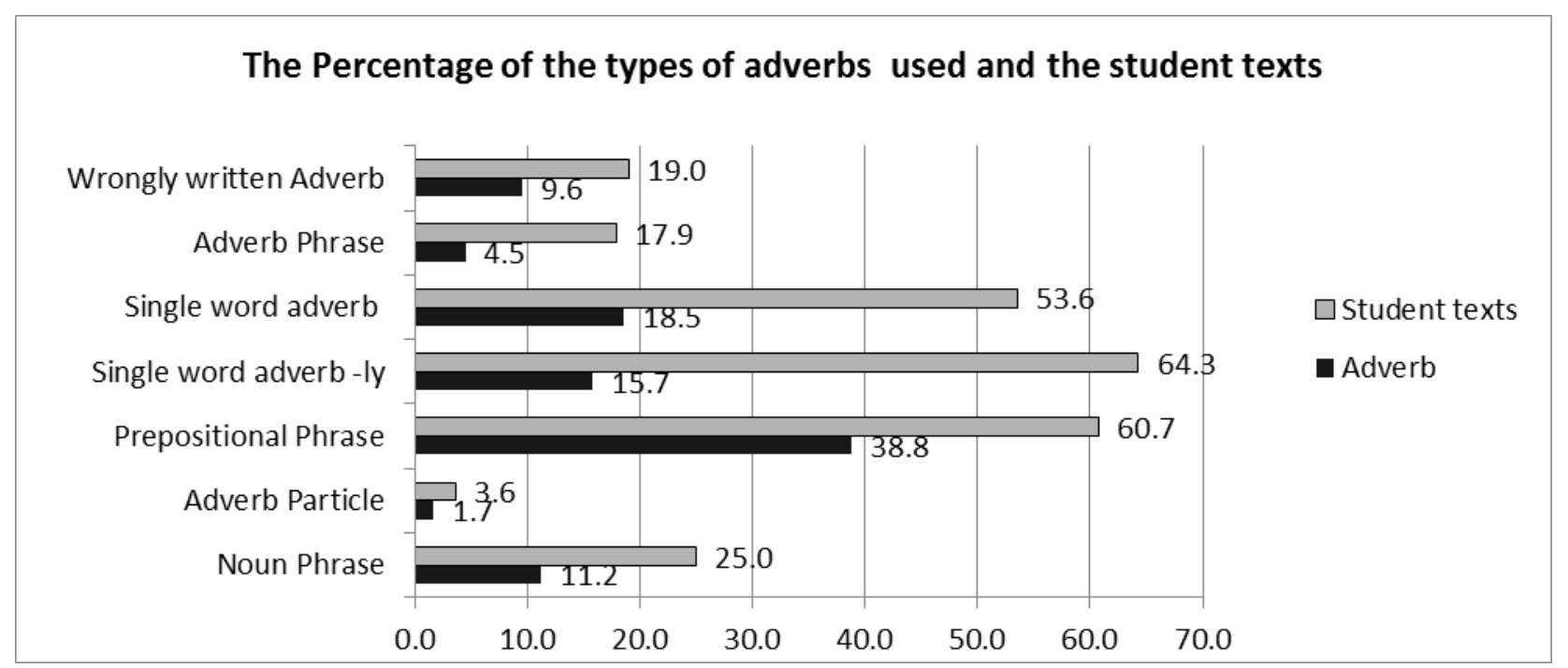

Source: Primary data

Figure 1. The percentage of students using the percentage of the types of adverbs in the letter of complaint

Another positional usage of adverb particle is that it is detached from the verb and put after the object when the object is a personal pronoun or when it is comparatively short. Another trend is that there are word forms used as both adverb particles and prepositions.

The nuances of the functional uses of the adverb particles as adverb and at the same time as prepositions do still belong to the areas of ambiguity and 'mystery' to many second language learners and users of English. On the other hand, it should be noted that even in the use of adverbs, $19 \%$ of the respondents used wrongly written adverbs which amounts to almost $10 \%$ of the total adverbs used. Carelessness in a situation of writing speedily could have been one factor.

An adverb phrase can mean a single adverb, "quickly" or an adverb phrase, "not only but also", 'very late' or an adverb particle, 'about', 'above'. However, an adverbial phrase can mean a noun phrase, 'that time', 'these days', 'next month' and a prepositional phrase, 'at night', 'before one month', 'in the Mannar town' used as adverbs. All adverb phrases are also adverbial phrases. Though an adverbial phrase does not have 'an adverb' in the traditional grammatical sense of the word, it performs as an adverb.

It is a meaning based or function based classification of the adverbs they used in the letter writing. As usual, they have used adverbs sufficiently to refer time - around seventy expressions of different nature to refer time. The adverbs of frequency are seen within the category of adverbs of time. The adverb of manner comes second totaling fifty five. The adverbs of degree, adverbs of focus, adverbs of quantity, and adverbs of attitude are also visible within the adverbs of Manner. The third major use is place. It is around forty.

Since prepositional phrases are mostly used as adverbs, the respondents used them to denote place predominantly, for example, in this area, in the area, in my area, in our area, in our district area, etc., at the secondary level, to denote time: in the mid night, in the morning time, in recent year and finally to denote manner: in a proper way, in the wrong way, in order etc. 
The respondents had the habit of repeating the use of the same types of adverbs throughout their discourse of letter writing. Figure 2 reveals that $18 \%$ of the respondents repeated the prepositional phrase (PP) as adverb two times; $14 \%$ single word adverb with -ly suffix (SWA -ly) and 9\% single word adverb (SWA). The rest of the types were almost avoided for the second time use. However, when it comes to three time use, only $9 \%$ use PP and SWA three times and SWA -ly by $6 \%$. There is a serious decline in repetitive use. In four times, it further goes down as 5\%, 0\% and 3\% respectively.

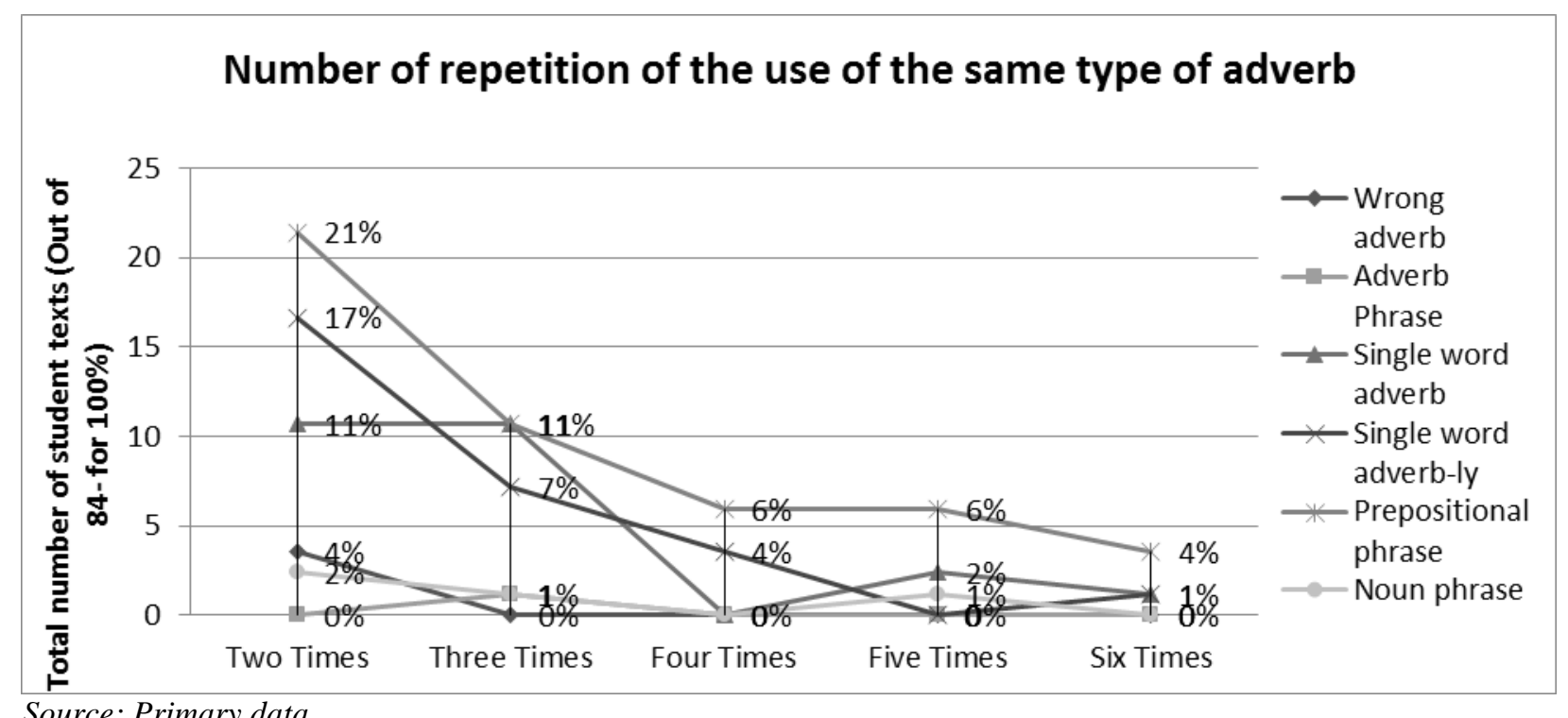

Figure 2.The repetition of the types of adverbs

Only PP is used by $5 \%$ for the fifth time and $3 \%$ for sixth time in their letter. Fifth time SWA comes back for $2 \%$ and $1 \%$ for the sixth time and SWA-ly completely goes down to zero with the rest in fifth time use and surfaces with $1 \%$ for the sixth time use. It can be concluded that PP is conveniently and generously used with SWA-ly and SWA coming after. Then a question rises why PP is easier compared to SWA-ly and SWA.

\subsection{The Position of the Adverbs used}

It is generally accepted that identifying an adverb within a sentence can be a problem to the learners especially differentiating it from an adjective, from a complement, from a preposition. On the other hand, identifying one type of adverb from the other can also be a problem especially an adverb phrase from an adverbial phrase and so on. In addition, there is an additional challenge- making rules in relation to their positioning in a sentence. The rules depend on traditional usage, flexibility of certain adverbs; the speaker's intended meaning and emphasis. Figure 3 reveals the positions the respondents choose to use their adverbs.

The genre of a complaint letter generally has a three-partite discourse structure starting with introduction and problematization, exploring into the consequences and concluding with suggestions and solutions. According to the analysis, majority of the respondents adopted this three partite discourse structure but linguistic structure, around $50 \%$ used three paragraphs to incorporate the three discourse structures; $30 \%$ used two paragraphs to cover the three discourse structures and $20 \%$ used only one paragraph to include these three discourse divisions. In the analysis of using adverbs in the initial, medial and final positions of the sentences, the analysis reveals as follows: In the first section Introduction and problems, $10 \%$ and $5 \%$ of the adverbs were used at the initial and medial positions respectively. However, $21 \%$ were used at the final position of the sentence. It shows that, for emphasis at the very beginning, the respondents used the adverbs at the initial position in the introductory discourse. However, in conforming to the traditional usage, majority of the adverbs were used at the final position.

In investigating the positions of the adverbs in the second section Consequences, there is an increase if the percentage of the adverbs used at the initial and medial positions $-15 \%$ and $8 \%$ respectively. Interestingly, there is a slight decrease in the final position $(18 \%)$. Here it is notable that the respondents have the courage to break away from the traditional final position use because they feel that the discourse structure is more important than the linguistic structure, in other words, meaning over sentence structure. Consequences are both informational and emotional and both behavioral and mental. It is of serious nature which should be communicated assertively. Therefore, the respondents venture to choose more front and medial positions. 
Adverbs in the initial, medial and final positions

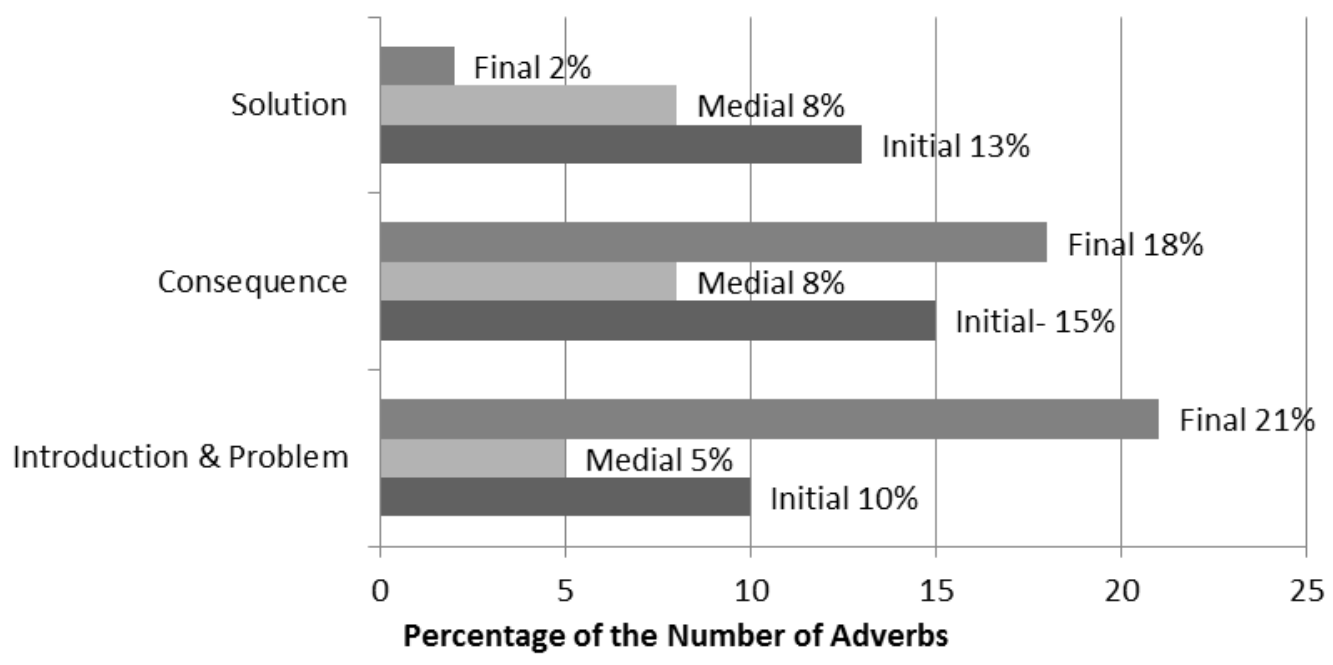

Source: Primary data

Figure 3. The adverbs used at the initial, medial and final positions

In the last section of saying about suggestions and solutions, the assertiveness and seriousness culminates pushing the positions of the adverbs almost to the front and the middle while downsizing the number at the final position, which is $13 \%, 8 \%$ and $2 \%$ respectively.

The final position of a sentence means at the end of the sentence or a clause. The medial position means before the main verb or after an auxiliary or modal auxiliary. The initial position means at the beginning of a clause/sentence. However, the respondents very rarely used the adverbs to describe or qualify an adjective, which means, before an adjective or before and adverb. It shows their poor proficiency in the use of adverbs in their overall functions. Further, it was noted that some students used -ly adverbs before an adverbial phrase.

The use of adverbs in the positions where it is unacceptable to place adverbs was also noted: between the verb and object of the sentence and between the verb and a clause beginning with to + an infinitive or a that-clause. Another complex area the respondents lack proficiency in the use of adverb in positions is that some set of adverbs do not follow the regular rules and they are negative in communication. Those adverbs have to be used at the beginning of a sentence like scarcely, not only, seldom, rarely, never and so on. As a result, the consequent SVO or SVC word order of the sentence will change to look like the question form inversing the auxiliary or helping verb and main verb forms, for example, never had I seen such a degrading performance; Not only does the doctor visit the school occasionally, but he also stays overnight in case of finding a large number of patients. Nobody used this negative adverb use with the inversed position.

\subsection{The Quantity of the Adverbs used}

Mostly they are used as adverbial phrases and the students find it easier, compared to their positions within other phrase structures as noun phrase and adverbial particles. They write the adverbial phrases with less noun phrases, for example, it is not surprising to observe that less students have used verb particle (the additional functions of prepositions when they join with verbs, for example, come up etc.) as adverbial particle in their writing. It shows that Sri Lankan students are still reluctant or ignorant to use adverbial particle comfortably in their creative writing.

Another area of investigation is the ability of the respondents in differentiating the function of an adverb phrase from that of an adverb clause. An adverb phrase is simply two or more words acting as an adverb modifying a verb, adverb, or adjective. Adverb phrase mostly answers the questions of "how", "where", "why", or "when." An adverb clause also modifies verbs, adverbs and adjectives while constituting a subject and a verb. It is mainly used for expressing time, condition, contrast, and cause and effect. The investigation of the above seven scripts reveal that only two respondents have used adverb clause only once in their letters - If you take immediate decision, our area people appreciate you (SN 41 P3:8); Even though we all have informed to the Electricity Board several times, still no action has been taken (SN 79: P3: 7 \& 8). The former is condition and the latter is contrast. The respondents lack fluency in using adverb clauses in their business communication. 
Table 1. The Performance in the texts of the seven students in the campus

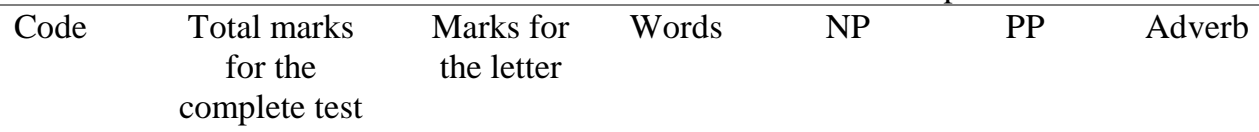

\begin{tabular}{ccccccc}
\hline 83 & 27 & 3 & 70 & 7 & 11 & 5 \\
\hline 31 & 40 & 4 & 84 & 9 & 10 & 8 \\
\hline 2 & 52 & 4 & 96 & 11 & 14 & 7 \\
\hline 18 & 55 & 4 & 110 & 12 & 10 & 8 \\
\hline 41 & 61 & 5 & 122 & 15 & 16 & 7 \\
\hline 37 & 72 & 7 & 116 & 10 & 12 & 8 \\
\hline 79 & 83.5 & 8 & 148 & 15 & 15 & 8 \\
\hline Average & $40-60$ & 5 & $70-150$ & 11.3 & 12.6 & 7.2 \\
\hline
\end{tabular}

(Total: the total marks of the complete test (3 hours testing all the four skills plus grammar); the letter: the marks given for the letter out of 10 marks; NP: the number of Noun Phrases; PP: the number of the prepositional Phrases; words: the number of words in the letter; Av: the average; Adverb: the number of adverbs in the letter)

Table 1 shows a case study of the texts of seven students. There is uniformity between the increase of marks in both the total test and the essay and that of the number of words used. There is balance in using prepositional phrases in par with noun phrases (around 10-15 in number). Though the lowest has used five adverbs and the highest performer has used ten adverbs, the average is 7.2. It reveals that the students do not show any inhibitions or reservations in using adverbs in their writings. The interesting trend is that most of the prepositional phrases used in the letters are adverbial phrases. Around $61 \%$ of the students have used prepositional phrases as adverbial phrases. Looking at the types of adverbs, prepositional phrases occupy $39 \%$ of the total adverbs used. However, using noun phrases as adverbs is $25 \%$ of the total respondents. Only $11 \%$ are the noun phrases used as adverbs out of the total adverbs used (See Figure No 1).

Figure No. 4 reveals the total number of the student texts per the total number of the adverbs used in each text. $5 \%$ of the respondents did not use any adverbs at all in their letter writing. A letter of complaint without adverbs referring time, place, and manner shows the ignorance or the lowest level proficiency in English communication. They lack the skills of analysis, synthesis, distinguishing ability, modification, attribution, and qualifying ability. 9.5\% used only one adverb in the whole letter. $18 \%$ used only two adverbs; $32 \%$ used 3 to 4 adverbs; $21 \%$ used five to seven adverbs; $14 \%$ used eight to ten adverbs. This statistics reveals that though 5\% did not use adverbs at all in their writing the rest used the adverbs significantly enough. Analyzing the seven scripts above reveals that the average number of adverbs used is 7.2. The average number of the total respondents (84) reveals that around $55 \%$ of the respondents used minimum four to five adverbs.

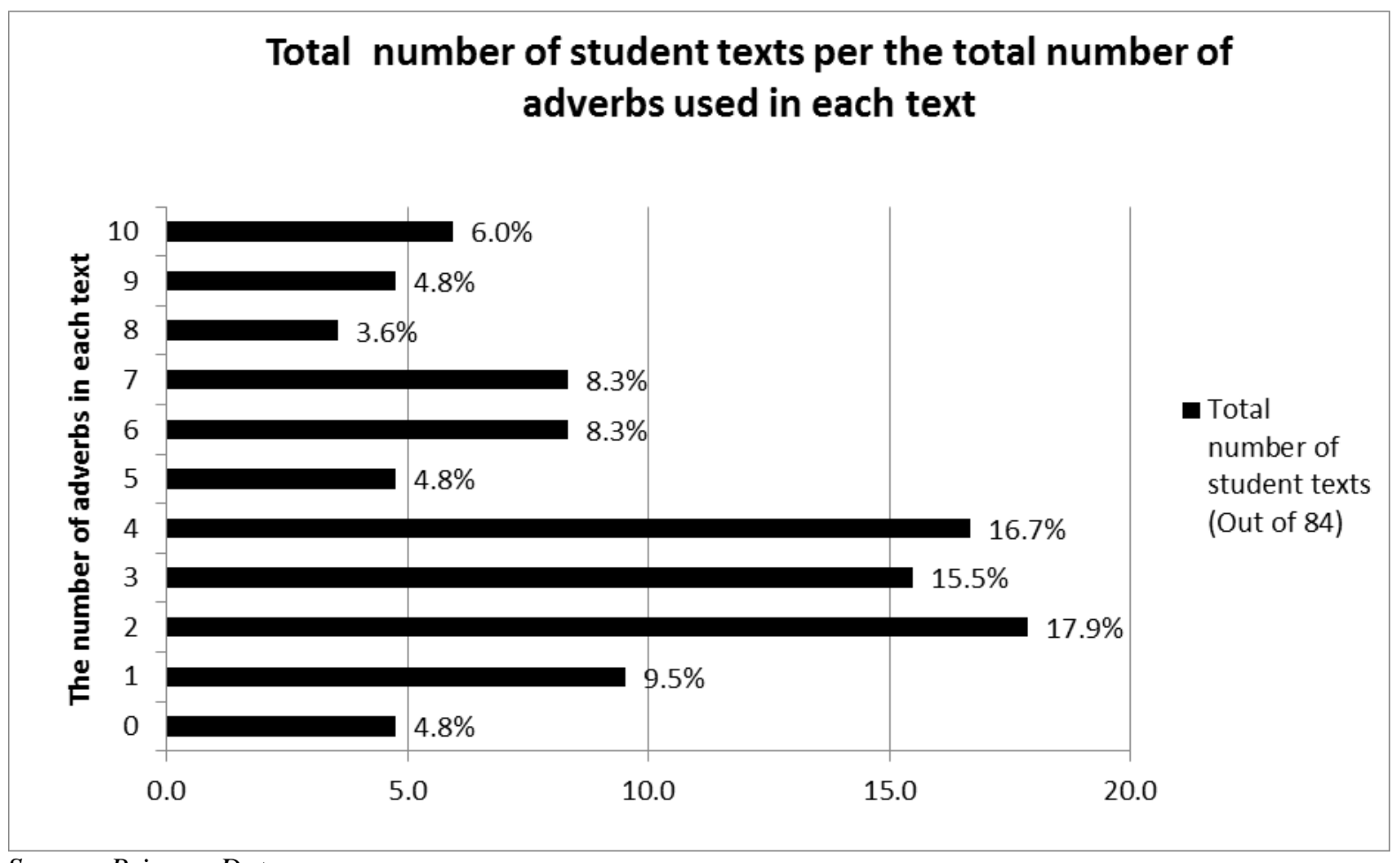

Source: Primary Data

Figure 4. The total number of the student texts per the total number of the adverbs used in each text 
The deviations in the use of adverbs have been listed and described below in Table 2. Collins Cobuild English Usage (2012) says 'shortly' is an adverb. In Deviation [AACE], the student seems to have chosen the meaning, immediately after the power cut, we have faced immense difficulties.... but another possibility is that due to the power cut, recent days or times, we have faced or have been facing immense difficulties.... The student attributes a new meaning, 'nowadays' or 'at present', or 'recent times'.

Table 2. Type of adverb deviations

\begin{tabular}{|c|c|c|}
\hline $\begin{array}{l}\mathrm{S} \\
\mathrm{N}\end{array}$ & $\begin{array}{l}\text { Type of Adverb } \\
\text { Deviation }\end{array}$ & Examples \\
\hline 1 & $\begin{array}{l}\text { [AACE] Article Adverb } \\
\text { Combination Error }\end{array}$ & $\begin{array}{l}\text { [22] In a shortly, we have caused immense difficulties in managing day } \\
\text { to day activities in our area. }\end{array}$ \\
\hline 2 & $\begin{array}{l}{[\mathrm{ABWP}] \text { Adverb in }} \\
\text { Wrong Place }\end{array}$ & $\begin{array}{l}\text { [45] Our main problem is our children can't studies in properly within } \\
\text { the evening \& night. } \\
\text { [66] Due to this problem, we can't managing our daily activities as } \\
\text { possibally. } \\
\text { [75] This day to day effects by our life. } \\
\text { [38] This activity is very affected all the people in our village. } \\
\text { [14] I hope you take your kindly consideration about this problem. } \\
\text { [38] This is my kindly requested to you sir. } \\
\text { [50] So please give the kindly consideration about this matter. } \\
\text { [58] It is my kindly request sir. } \\
\text { [20] We will expect your well work. } \\
\text { [26] That typically power cut due to difficult reason affect in our day to } \\
\text { day life. } \\
\text { [32] These unexpectly power cuts create more difficulties in our day to } \\
\text { day life. }\end{array}$ \\
\hline 4 & $\begin{array}{l}\text { [DAB] Adjective As } \\
\text { Adverb }\end{array}$ & $\begin{array}{l}\text { [24] Electricity power supply our areas difficulties day to day } \\
\text { [57] We all are aspect roper or sharp electrical power to do our casual } \\
\text { work in orderly. }\end{array}$ \\
\hline 5 & $\begin{array}{l}\text { [DUSAB] Double Use } \\
\text { of the Same Adverb }\end{array}$ & [43] We could not be performed our tasks well well. \\
\hline 6 & $\begin{array}{ll}\text { [SSMA] Starting a } \\
\text { Sentence with Many } \\
\text { Adverbs }\end{array}$ & [38] Continuously too or three weeks suddenly the power was cut. \\
\hline 7 & $\begin{array}{l}\text { [UABU]Unnecessary } \\
\text { Adverb Use }\end{array}$ & [44] I would kindly thank you, if you solve the problem immediately. \\
\hline 8 & $\begin{array}{l}\text { [WAP]Wrong adverb } \\
\text { Phrase }\end{array}$ & $\begin{array}{l}\text { [22] Therefore please give your attention about this matter and } \\
\text { informing your schedules of power cuts earlier as possible. } \\
\text { [26] As well as quickly please you take a decision. } \\
\text { [56] This time somewhat think what happening in their homes. }\end{array}$ \\
\hline 9 & $\begin{array}{l}\text { [AVS] Adverb Verb } \\
\text { Subject Wrong Order }\end{array}$ & [7] The area's living for 500 school studen's. \\
\hline
\end{tabular}

The student's intention is ambiguous in Deviation [ABWP]- 'in properly' can mean 'improperly' which also has some pragmatic issues like 'is it because of the way they study or the power cut? However, using a preposition in front of an adverb is not admissible as seen in [AACE]. In the second sentence, another example is shown. American Heritage (2011) says that it is an adjective. The student is ambiguous here. This writing can mean 1) this affects our day to day life and 2) This has a day to day effect on our life. The student is confused about the distinct functional meanings of affect (verb) and effect (noun) and about using the adjective as adverb. The adverb 'very' needs 'much' consequently and 'has' replacing 'is' in preceding position: this activity has very much affected all the people in our village. The student has confusion over the adverb and adjective phrases coinable with the adverb form, 'very', and the relevant voice in the verb use.

In Deviation [AVA], the word 'kindly' can be used as an adjective (kindlier, kindliest) as well as an adverb. As an adjective it can mean showing, or proceeding from a benevolent disposition or spirit; kindhearted: kindly people. As an adverb, it can. However, kindly as adjective is not used with the nouns 'consideration' and 'request' instead, kind is used. One the other hand, 'my kindly requested 'shows the confusion in using request as a noun or verb. The adverb, 'well', is used as adjective which can be 'good'. The adjectives typical and unexpected replace the adverb forms used. One thing is notable here. The student shows competence in using past participle verb forms- both positive and negative adjectives and adverbs with - ly. 
These are all frequently seen in formal invitations and such. They are in the "expected" format. As with all language of courtesy, there is no need for getting too worked up over what each word literally means in these frozen, fossilized forms. They have become formulaic, so it is "what people do" on such occasions.

The adjectival expression, day to day, in Deviation $[\mathrm{DAB}]$ is used as adverb. The adjective, 'orderly' is used as adverb with an additional deviation: preposition with adjective as an isolated form. In Deviation [DUSAB], the deviation shows the notion of double time use of an expression as an emphatic or reinforced idea.

It is prevalent in the native Sri Lankan languages, Tamil and Sinhala. In Deviation [SSMA], although it is acceptable to start a sentence with an adverb, adverb phrase, or adverbial phrase, this distorted use of almost four adverbs is not appropriate. In Deviation [UABU], there is no need for 'kindly' to thank somebody.

In Deviation [WAP], the standard form needs a preposition- as early as possible. Here the student has used a comparative form earlier. This is not usual. In the second sentence, it can be please take a decision as quickly as well. In the third sentence, though the adverb, somewhat is used, it needs clarification. It means a moderate extent or by a moderate amount; rather, for example, "matters have improved somewhat since then". Usually the adverb comes after the verb; this sentence has it vice versa without a subject as an instruction. In Deviation [AVS], in the first sentence, the word order is as follows: 500 school students live in this area. So the adverb is positioned in front.

\section{Findings}

The findings confirm that the ESL users or learners master the use of adverbs in English at the surface level without understanding the deep level implications and nuances. Their use of adverbs shows a confused or ambiguous qualified or quantified relationship with an action denoted by a verb or its equivalent in contrast to consider 'adverbial emphasis as a receptive intensification' (Pérez-Paredes and Díez-Bedmar, 2012). Compared to meaning and function based use of the adverbs, the sentence or linguistic structure based use of adverbs lack diversity. As Zi-hong (2010) stated, the difficulty of capturing the rhetorical repositioning while "learning or acquiring the syntactic positions of adverbs in English" (p. 50) is identified in this research. The average number of the total respondents reveals that generally the students use minimum four to five adverbs in their letter consisting around 120 words in average. It seems acceptable. However, when a sample of seven selected scripts based on the score obtained progressively revealed that the average is almost eight adverbs. However, as mentioned before, they lack diversity of types and functions.

The use reflects maturity in terms of time, place and manner or process functions. However, though the adverbs of degree, adverbs of focus, adverbs of quantity, and adverbs of attitude are also visible within the adverbs of Manner, the competency for differentiating the taxonomy of adverbs within the adverbs of manner or process is lacking among the students. Another area of difficulty for distinguishing the different functions is the adverbial and complementary functions.

The majority of Sri Lankan university students ignore the nuances in producing and recognizing and using the sentence structure based types of adverbs, adverb phrases, adverbial phrases and adverbial clauses, sentence adverbs and the different types and uses of adverb phrase from adverbial phrase. The prepositional phrase, single word adverb and single word adverb with -ly suffix are considerably used in adverbial function. Adverb particle, noun phrase, adverbs with the -edly suffix, sentence adverbs and adverb clauses are not very much in use. In addition, the differentiating ability between adverb and adjective words, phrases and clauses is also insufficient. The respondents could not extend the role of adverb to 'express degree and limit adjectives or other adverbs (Baskervill and Sewell, 1896:18 as cited in Nuhiu, 2014).

The analysis of the repetitive use of the adverbs further confirm the above mentioned point about the efficient and effective use of the meaning based and sentence based classification of adverbs. Primarily prepositional phrase, then SWA, and SWA-ly are used in repetition. Then a question rises why Prepositional Phrase is easier compared to SWA-ly and SWA. The respondents confirmed Delfitto's (2006) amusement about "adverbial syntax leading to quite puzzling questions concerning the interplay between issues of placement and issues of movement" (p. 103). The students lack the competence in the extensive taxonomy of the meaning based and sentence based adverbs and their structural and functional uses. Prepositional phrase is a universal feature used and usable as representative unit conveniently and generously in almost all the parts of speech in the traditional sense of the word as they are also parts of speech (Kabashi, 2000:20 as cited in Nuhiu, 2014). Students are just aware of the visible surface level units such as 'prepsotion+article+adjective+noun' in isolation, not as a holistic unit representing the type and function called adverbial.

The students face an additional challenge - adverb shifting position causing problems for ESL students (Hernández, 2006)- understanding and applying rules in relation to their positioning in a sentence. The rules depend on traditional usage, flexibility of certain adverbs; the speaker's intended meaning and emphasis. The genre of a complaint letter generally has a three-partite discourse structure starting with introduction and problematization, exploring into the consequences and concluding with suggestions and solutions. It shows adverbial fronting (Hewings, 2005) that, for emphasis at the very beginning, the respondents used the adverbs at the initial position in the introductory discourse. However, in conforming to the traditional usage, majority of the adverbs were used at the final position as the position after the main verb is generally considered as its usual position (Koffi, 2010, p. 276). However, there is an increase if the percentage of the adverbs used at the initial and medial positions in the sections of Consequence and Solution respectively. Here it is notable that the respondents have the courage to break away from the traditional final position use because they feel that the discourse structure is more important than the linguistic structure, giving importance to 
'the rhetorical emphasis of adverb repositioning' (Dissosway \& Hartford, 1984), in other words, meaning over sentence structure (Baskervill and Sewell, 1896:282-87 as cited in Nuhiu, 2014). In addition, most of them lack distinctive use of adverbs of exceptional types such as negative adverbs - fronting and inversing- and of exceptional functions. As Macaulay, (2002) pointed, most of the respondents lack good educational background and social class (middle) to determine efficient use of adverb movement strategies more effectively as they are from poor educational background and lower class.

Finally, in committing errors or deviations in adverb use, it is notable that compared to the percentage of quantitative and qualitative errors or deviations in the use of articles, prepositions and tenses, it is very less in adverb use. This study suggests a need for 'a focused position on adverb placement' (Dissosway \& Hartford, 1984) in learning.

\section{Conclusion and Suggestions}

This research intensively investigates the types, functions, positions, quantity and quality and deviations of the adverbs used by the respondents, the undergraduates of the Bachelor of Business Management degree program of Vavuniya Campus of the university of Jaffna, Sri Lanka. Most of them fail to acquire the distinctions and implications correctly in their typical structures and functions. The majority of textbook writers and syllabus designers do not distinguish the functional meanings of adverbs from their typical structures when they are used within the reading passages and listening sessions. Therefore, many students are confused in the distinct and non-distinct uses of the adverbs functionally and structurally. A substantial recommendation can be that the Sri Lankan school text book and syllabus designers should incorporate a comparison of the functional and structural use of respective group of the types of adverbs semantically and pragmatically and linguistically at micro- and macro-levels.

\section{Reference}

Al-Baghdadi, S. Sattar, (2003).The Achievement of College Students in Using And Placing Single-Word Adverbs in Their Appropriate Position. Baghdad: Al-Mustansirya University College of Arts. Retrieved Feb 62016 from http://www.iasj.net/iasj?func=fulltext\&aId=29156

American Heritage Dictionary of the English Language, (2011). Houghton Mifflin Harcourt Publishing Company. Fifth Edition.

Baskervill, W. M. \& Sewell, J. W. (1896). An English Grammar. Longman. Gmbh Hamburg, Germany

Collins COBUILD English Usage. (2013). Princeton: HarperCollins Publishers. Princeton University, Farlex Inc.

Collins Thesaurus of the English Language. (2002). HarperCollins Publishers.

Crystal, D., (1980). A First Dictionary of Linguistics and Phonetics, Cambridge: Cambridge University Press.

Delfitto, D. (2006). Adverb classes and adverb placement. In M. Everaert \& H. van Riemsdijk (Eds.), The Blackwell companion to syntax (83-120). Malden, MA: Blackwell Publishing. Retrieved Feb 62016 from http://www.univr.it/documenti/AllegatiOA/allegatooa_14152.pdf

Dissosway, P., \& Hartford, B. (1984). Errors and adverbs: What we teach and what ESL students actually do. Paper presented at annual meeting of teachers of English to speakers of other languages. Houston, TX. Retrieved Feb 62016 from https://ia902603.us.archive.org/14/items/ERIC_ED243323/ERIC_ED243323.pdf

Eastwood, J. (1999). Oxford Practice Grammar. Oxford: Oxford University Press.

Eckersley, C.E. and J.M. Eckersley, (1966). A Comprehensive English Grammar for Foreign Students, London, Longmans, Green and Co., Ltd

Finch, G., (2000). Linguistic Terms and Concepts. London: Macmillan press LTD

Gnanaseelan, J. (2014). A Corpus Analysis of the Prepositions used in Letter Writing in English. Research Chronicler. Vol.II. Issue III. ISSN 2347-503X. pp.1-15. Retrieved Feb 62016 from http://www.researchchronicler.com/pdf/v3/2301.pdf

Hernández. M. S. (2006). The position of adverbs in English: Trying to solve a major problem most language learners usually face. Filología y Linguística, 32(1), 271-285. Retrieved Feb 62016 from http://revistas.ucr.ac.cr/index.php/filyling/article/viewFile/4332/4155

Hewings, M. (2005). Advanced grammar in use: A self-study reference and practice book for advanced learners of English. Cambridge: Cambridge University Press. Retrieved Feb $6 \quad 2016$ from http://anianetart.nazwa.pl/ksiazki/Advanced-grammar-in-use-Martin-Hewings.pdf

Jacobson, S. (1964). Adverbial positions in English. Stockholm: AB Student book.

Kabashi, J. (2000). English "Grammar: Morphology. Prishtina: The University of Prishtina.

Koffi, E. (2010). Applied English syntax: Foundations for word, phrase and sentence analysis. Dubuque, IA: Kendall Hunt Publishing Company. Retrieved Feb 62016 from https://he.kendallhunt.com/product/applied-english-syntaxfoundations-word-phrase-and-sentence-analysis-ebook 
Macaulay, R. (2002). Extremely interesting, very interesting, or only quite interesting? Adverbs and social class. Journal of Sociolinguistics, 6(3), 398-417. Retrieved Feb 62016 from http://onlinelibrary.wiley.com/doi/10.1111/14679481.00194/abstract

Nuhiu, Majlinda. (2014). Morphological contrastive analysis of adverbs in English and Albanian language. European Journal of Research on Education, Special Issue: Contemporary Studies in Education, 98-102. ISSN: 2147-6284. Ejournal 2013. Retrieved Feb 62016 from http://iassr2.org/rs/020416.pdf

Pérez-Paredes, P., \& Díez-Bedmar, M. B. (2012). The use of intensifying adverbs in learner writing. In Y. Tono, Y. Kawaguchi, \& M. Minegishi (Eds.), Developmental and cross linguistic perspectives in learner corpus research (105133). Philadelphia: John Benjamins Publishing Company. Retrieved Feb 62016 from http://www.academia.edu/4365207/The_use_of_intensifying_adverbs_in_learner_writing

Rutledge, James and Fitton, Zachary (2015). "Teaching ESL Students Adverb Position to Develop Rhetorical Emphasis," Linguistic Portfolios: Vol. 4, Article 12. Retrieved Feb $6 \quad 2016$ from http://repository.stcloudstate.edu/stcloud_ling/vol4/iss1/12

Thomson, A.J. and A.V. Martinet, (1980). A Practical English Grammar, 3 rd. ed., Oxford University Press

Quirk, R. and Greenbawm, S. (1990). A Student's Grammar of the English Language, Longman.

Zi-hong, Z. (2010). The syntactic positions of adverbs and the second language acquisition. Sino-US English Teaching,

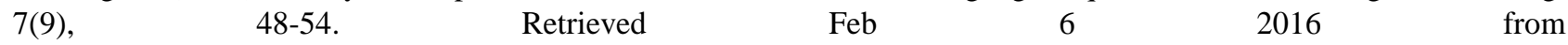
http://www.davidpublishing.com/davidpublishing/Upfile/4/18/2012/2012041884781969.pdf 